\title{
Research on the Inheritance and Transformation of College Students' Employment and Entrepreneurship from the Perspective of New Media
}

\author{
Chunlei Zhou \\ Henan University of Traditional Chinese Medicine, Zhengzhou, Henan 450000, China
}

\begin{abstract}
. in this article, through analyzing the current situation of employment and entrepreneurship, and put forward the use of new media to promote employment and entrepreneurship theory analysis, and to strengthen the employment guidance, set up information platform, establishing employment feedback mechanism as the starting point to talk about their own views, in order to cause the government, unit of choose and employ persons, the three of universities, gradually built up by the new media as a platform of college graduates service network, effectively solve the problem of university students' employment.
\end{abstract}

Keywords: new media, university students, employment and entrepreneurship, inheritance and transformation.

\section{Introduction}

In 1967, p. Goldmark, President of CBS technology institute, first put forward the concept of new media. Compared with traditional media such as radio, television, newspapers and magazines, new media make extensive use of digital technology, mobile technology and network technology, and rely on Internet, wireless communication network, satellite and other platforms as well as terminals such as computers, mobile communication equipment and digital television to provide users with the information and services they need. With the rapid development of information technology, new media has rapidly changed the daily study and life of teachers and students in colleges and universities, exerting a profound impact on their outlook on life, values and morality. As a base to train and deliver outstanding young talents, under the great employment pressure, colleges and universities must make good use of the trump card of new media to carry forward and transform the employment and entrepreneurship of college students.

\section{Analysis of the Current Situation of Employment and Entrepreneurship of College Students}

According to statistics from the ministry of human resources and social security, the number of college graduates in China in 2014 is expected to reach 7.57 million, an increase of nearly 300,000 over 2013 and the highest ever. According to the 2013 "employment report of Chinese college students", in recent years, about $10 \%$ to $15 \%$ of students are unable to find employment every year, which accumulates and makes it more and more difficult for college students to find employment in the future. Although in recent years, the government departments to take measures to promote the university students' employment, and issued a series of policies to encourage college students self-employment, but from the actual situation of university students' employment difficult problems has become a fact, entrepreneurial winners are much rarer, and has become a topic of common concern to society and the problem to be solved at all levels of government.

\subsection{College Education}

In recent years the party and the country attached great importance to the development of higher education, invest a lot of, material and financial resources and some colleges and universities are not relying on its own characteristics, not from the perspective of market demand, pure expanded recruitment of students scale, blind add professional, matriculate quality decline year by year, causing most of the students can't find the ideal job, not knowledge. In addition, colleges and universities 
often only attach importance to imparting the basic theory of knowledge, although some colleges and universities also try to practice into the whole teaching content, and the entrepreneurship education courses, but the lack of perfect system of employment and entrepreneurship education, ignore the information platform and media role, so students can obtain knowledge cannot adapt to the demand of the society.

\subsection{Students' Own Problems}

According to the survey of several famous recruitment websites in China, more than $60 \%$ of the graduates think that the employment situation is not good and it is difficult to find a job. However, there are also $50 \%$ of the graduates are not willing to accept lower salary or start from the basic position. The main reasons for this phenomenon are as follows :(1) outdated concept of employment. Many college graduates choose Beijing, Tianjin, Shanghai, Guangzhou and other cities along the eastern coast as their first choice for employment, but few in the central and western regions or in remote areas. At the same time, the nature of the work, working hours, labor remuneration, etc. With the craze for civil servants and public institutions in recent years, graduates would rather give up their majors and dreams and struggle for life in order to secure a stable job. (2) lack of knowledge and skills. Many students think that there will be no pressure when they get to college, and they begin to relax their requirements. After four years, they have hardly mastered basic professional knowledge. (3) lack of entrepreneurial ideas. Since employment is not available, many college students choose to start their own businesses. However, most of the students have a very simple understanding of entrepreneurship. They decide to start their own business projects based on their enthusiasm, or engage in low-skilled industries such as tutoring, catering and service industries, and finally fail.

\subsection{The Function of Government}

China's education system and existing policies cannot keep up with the rapid pace of economic development, and many departments only pay lip service to it, hold meetings or hold several job fairs, and only put the promotion of employment on the surface or as part of their achievements. At the same time, the government's information propaganda on encouraging college students to find jobs and start businesses is not in place, and many college students' entrepreneurial behaviors are not supported by parents, schools and the society. In some places, there is insufficient support for students to start their own businesses, or the approval procedures are complicated and the promises are not fulfilled in time, which leads to the decrease of students' entrepreneurial enthusiasm, the lack of capital for start-up projects and the failure of entrepreneurial behaviors.

Second, the idea of realizing the inheritance and transformation of college students' employment and entrepreneurship from the perspective of new media

Relying on the traditional media to release employment information and carry out employment and entrepreneurship guidance has been unable to meet the actual needs of college students, and the rapid development of new media is providing opportunities and challenges for college students employment and entrepreneurship. How colleges and universities make good use of the advantages of new media is a new direction that educators need to focus on and research. Today's college students with new media has a large amount of information and communication, strong interactivity, the advantages of the wide spread rapidly, anywhere "send WeChat messages" "sun Weibo", thus on the one hand, colleges and universities can take advantage of the official WeChat, official Weibo, campus BBS and other new media actively, to release the policy of employment and entrepreneurship and information on a large scale; On the other hand, the employing units can release the employment demand and publicize the enterprise culture and advantages by virtue of the network platform. In addition, relevant information can be spread quickly among students. In this way, the traditional mode of unified employment guidance for students and the recruitment fair in graduation season has been completely changed. Students can obtain education and information at any time and any place, which greatly enhances their initiative in employment and entrepreneurship and improves their success rate.

Iii. The principle of carrying forward and transforming the employment and entrepreneurship of college students from the perspective of new media 
From the perspective of new media, the basic principles followed by the inheritance and transformation of college students' employment and entrepreneurship determine the development orientation and future direction of this work. Therefore, university educators must achieve coordinated development, authentic authority, information symmetry, to complete the mission given by history.

Coordinated development: new media perspective of college students' employment and entrepreneurial heritage transformation is a systematic project, needs the decision makers fully deployed, unified planning, the informationization promoting employment and pioneering work as a long-term, continuous work to grasp, equipped with special personnel and funds, and gradually form a complete set of management system and campus culture, make the school really attach importance to the work, up and down to the campus departments closely and all show solidarity, can enhance the level of college students' employment and entrepreneurship.

Authentic authority: although virtual media has become an important source of information, it is also full of false and deceptive information. Released at the same time due to network anonymity, the credibility of network information has become hinder the development of the primary factors, which makes the lack of social experience of college students in employment and entrepreneurship transmission through the network information have to careful to distinguish, even so there are a lot of students were cheated and even into the trap of pyramid selling. Therefore, as the main body of education, colleges and universities must ensure the true authority of network information.

Information symmetry: there is an old saying in China that only by knowing yourself and your enemy can you win every battle. In today's society, the accuracy of intelligence and information determines the direction and result of the situation. Those who are on the information side will have the initiative, while those who are on the information side will be cheated. Since the reform and development, the college entrance examination system in China has been relatively mature, employment patterns have also been transition from "assigned" to "two-way choice", although has obtained certain achievements, but also exposed some problems, especially the college graduates and unit of choose and employ persons and the asymmetric information between and among has become one of the important cause leading to the college students' employment difficulty. Firstly, there is information asymmetry between universities and students. After the college entrance examination, students and parents in colleges and universities and professional choice, although each school hold the recruitment of students propaganda, but for students and parents, in a short period of time to learn more about the related content, it is impossible to accurately grasp the employment situation of the specialty, and the lack of targeted employment education in colleges and universities, it is easy to cause unemployed is the result of four years' time. Secondly, information asymmetry exists between universities and employers. The main task of colleges and universities is daily teaching, teaching student's basic knowledge, so it is difficult to timely grasp the employer's latest requirements for talent. Even if we are aware of the change of market demand, changing the professional setting and talent training mode under the current system cannot be accomplished overnight. However, the lack of understanding of the professional characteristics and cultural background of colleges and universities will result in the sameness of assessment indicators or the ranking of schools, which will discourage the enthusiasm of students. Finally, information asymmetry exists between employers and college graduates. At present, the widely used recruitment process is that employers release job requirements, graduates deliver resumes according to their own professional direction and interests, employers screen and select the best candidates according to the situation of resumes. In fact, in this process, both sides will, for some reason or for their own interests, provide false information to confuse each other. Many employers try to attract or deceive outstanding college students by promising preferential treatment or changing professional terms. At the same time, some graduates also exaggerated personal quality and work ability, bring unnecessary losses to employers. Therefore, to ensure the information symmetry of multiple parties is a necessary guarantee for the employment and entrepreneurship inheritance and transformation of college students in the new media era. 


\section{Approaches to Realize the Inheritance and Transformation of College Students' Employment and Entrepreneurship From the Perspective of New Media}

\subsection{Use New Media to Guide a Correct View of Employment}

Although most college graduates have been able to clearly position themselves and choose the right job, there are still many graduates who cannot rationally understand themselves and are divorced from the reality in the concept of employment. And in some lower grade students, also generally lack of career planning, think to find a job is the fourth grade to consider things, lack of goal-oriented. Therefore, college educators can strengthen the guidance of college students' employment outlook with the help of new media and help them establish correct employment values. On the one hand, strengthen the ideological education of college students, through the new media to publicize a positive and correct view of employment, set a good example; On the other hand, new media should be used to timely guide college graduates to determine their employment destinations according to their actual conditions, so as to cultivate their job-seeking consciousness with the goal of improving their own ability and realizing social value.

\subsection{Build an Employment and Entrepreneurship Information Service Platform to Ensure the Authenticity and Reliability of Information}

"We will build a multi-level and multi-functional employment information service system, strengthen the statistics, analysis and release of employment information, and improve skills training, employment guidance and policy consulting services," it said. The outline of the national plan for medium - and long-term education reform and development (2010-2020) also clearly stated that "information technology has a revolutionary impact on the development of education, so great importance must be attached to it, and employment and entrepreneurship education and employment guidance services should be strengthened". With the rapid development of higher education in China, both the party and the country have put forward new requirements for the employment informatization construction of college graduates. Raging ten years ago, in response to the outbreak of SARS, effectively solve the problem of the employment of university graduates that year, the ministry of education to create a "college graduates employment information service network", the students' employment intention and units of fellow workers demand and posted on the Internet and integrate together to make the supply and demand both sides never leave home can obtain employment information, both control the flow of the staff, and promote the university students' employment. In 2006, in order to further strengthen the government, colleges and universities, graduates and unit of choose and employ persons the optimization of resources integration, and most potential play the function of the service, the ministry of education joint parts more established the "national college students' employment network alliance", each year the alliance held four network recruitment, easing the employment pressure of college students, the effect is remarkable. Then in 2009, a fusion of the domestic various provinces almost all colleges and universities "national college students' employment information service system", marks the employment of university graduates across the country the basic structure of information sharing mode, also revealed our country began to college students' employment and entrepreneurship work the prelude of the transformation from traditional mode to the new media era. Nearly three years mobile phone, tablet, WeChat, Weibo widespread use, make network technology thoroughly into the daily life of ordinary college students, so all departments and universities should be further development to build in the terminal and platform of university students' employment system, release the real, the authority of the employment and business information, make information more "ground". When the employment information network of Nankai university, Tianjin university and other universities releases the recruitment notice of the unit, they need to verify the specific situation of the unit in detail, so as to be responsible for the students. 


\subsection{Establish the Employment Information Feedback Mechanism}

On the one hand, the high employment rate of colleges and universities; on the other hand, it is true that students cannot find ideal jobs. This contradiction highlights the lack of employment information feedback mechanism construction in China. Therefore, only by establishing an effective graduation information feedback mechanism can we obtain the actual employment information of graduates more accurately. On the one hand, colleges and universities should improve their employment information network or alumni network to track the actual employment units or whereabouts of each graduate on a regular basis. Can through the alumni association and other groups, using various chat platform or E-mail for dynamic tracking, and can network in the form of questions and answers, according to the employment situation of graduates in the investigation, understand the student's ideological and psychological change, adaptation to society, to pay and job satisfaction and professional skills to promote the related content, which can cause the resonance of the graduates, and can obtain first-hand information. On the other hand, the employing unit has an important right of speech to test the quality of talent training in colleges and universities. Many colleges and universities will conduct interview and questionnaire survey on employers through return visit, network and employment information service platform, so as to timely grasp relevant information of graduates and adjust teaching contents in a targeted way. In the new media era, the feedback mechanism built through the information platform can effectively build a bridge to communicate with the three parties, locate the three parties more quickly and accurately, and effectively guarantee the information accumulation among the three parties.

\subsection{Use New Media to Hold Virtual Recruitment and Launch Entrepreneurship Competition.}

Only you program of Tianjin satellite TV has been widely concerned since its launch, which reflects the potential of new media in promoting college students' employment and entrepreneurship. The student associations of various colleges and universities can use the new media information platform as the carrier to guide students to make resumes and defense PPT, organize mock job fairs, hire teachers and personnel of relevant enterprises and units as judges, and give comments and references for job hunting positions according to the candidates' on-site performance, so as to improve the college students' awareness of job hunting competition. At the same time, on the basis of the existing various innovation and entrepreneurship competitions based on the "challenge cup", colleges and universities can use the new media platform to carry out the entrepreneurship idea competition to lower the entry threshold, shorten the entry time and expand the scope of participants.

To solve the employment pressure of college graduates is an important part of building a harmonious socialist society. Facing the increasingly fierce social competition, to solve the employment problem of the majority of young students is the party and the government's care and love for them. Now the new media era has penetrated into our daily life, and its influence will be more and more profound. College educators should make good use of this platform to help young students successfully complete the transformation from "campus person" to "social person", and undertake the historical mission of college graduates' employment and entrepreneurship inheritance and transformation.

\section{References}

[1]. zhou xiao. Analysis of new media industry pattern and development trend [J]. Television research, 2011,1 .

[2]. $\mathrm{xu}$ wenjie, jin tianxing, zheng man. On the asymmetry of college students' employment information from the perspective of new media [J]. Journal of Hebei university (philosophy and social science edition),2011(4):139.

[3]. China's state council. Outline of national medium - and long-term education reform and development plan (2010-2020) [R]. Beijing: people's publishing house,2010. 
[4]. general office of the CPC central committee, general office of the state council. National informatization development strategy 2006-2020 [R]. Beijing: China legal publishing house, 2006.

[5]. tang yi. Research on college communist youth league's employment service for college students in the new era $[\mathrm{M}]$. Southwest university, 2009. 